\title{
Sudden cardiac death in a patient with advanced hepatocellular carcinoma with good response to sorafenib treatment: A case report with literature analysis
}

\author{
LINDA CALISTRI $^{1}$, CESARE CORDOPATRI $^{1}$, COSIMO NARDI $^{1}$, ELENA GIANNI ${ }^{2}$, \\ FABIO MARRA $^{2}$ and STEFANO COLAGRANDE ${ }^{1}$ \\ ${ }^{1}$ Department of Experimental and Clinical Biomedical Sciences, Radiodiagnostic Unit n. 2, \\ University of Florence-Azienda Ospedaliero-Universitaria Careggi; ${ }^{2}$ Department of Experimental \\ and Clinical Medicine, University of Florence, I-50134 Florence, Italy
}

Received August 2, 2016; Accepted October 19, 2016

DOI: $10.3892 / \mathrm{mco} .2017 .1132$

\begin{abstract}
Hepatocellular carcinoma (HCC) is the principal primary liver tumor, representing the third largest cause of cancer-associated death worldwide. The actual reference standard systemic treatment for advanced HCC is represented by sorafenib, a multi-targeted orally active small-molecule tyrosine kinase inhibitor. Sorafenib has exhibited a good general safety profile in multiple clinical trials. However, adverse drug-associated events are common, occasionally severe, and special attention should be paid to cardiovascular adverse events, particularly in patients with risk factors or known heart disease. In the present study, the case of a patient with no known cardiovascular risk factors affected by highly enhancing advanced HCC in cirrhotic liver, who died during successful sorafenib monotherapy, is reported.
\end{abstract}

\section{Introduction}

Hepatocellular carcinoma (HCC) is the most common primary liver cancer, with an incidence of approximately 780,000 new cases worldwide each year. It is also the third largest cause of cancer-associated death, with 745,000 deaths per year (1). Chronic liver disease, particularly cirrhosis, is the major risk factor for HCC development.

According to the Barcelona Clinic Liver Cancer (BCLC) staging system (2), advanced HCC is defined as follows: Unresectable HCC with extrahepatic spread (metastases or

Correspondence to: Professor Stefano Colagrande, Department of Experimental and Clinical Biomedical Sciences, Radiodiagnostic Unit n. 2, University of Florence-Azienda Ospedaliero-Universitaria Careggi, Largo Brambilla 3, I-50134 Florence, Italy

E-mail: stefano.colagrande@unifi.it

Key words: hepatocellular carcinoma, sorafenib, tyrosine kinase inhibitor, vascular endothelial growth factor, sudden cardiac death, case report lymph nodes involvement) and/or vascular invasion (portal or segmental invasion) and/or systemic symptoms; Eastern Cooperative Oncology Group performance status 1 or 2; Child-Pugh score not higher than class B $(3,4)$.

Sorafenib is a multi-targeted, orally active small-molecule tyrosine kinase inhibitor (TKI) that inhibits RAF kinase and the vascular endothelial growth factor receptor (VEGFR) intracellular kinase pathway (5). Sorafenib monotherapy is the actual reference standard systemic treatment for advanced HCC, as demonstrated in the Sorafenib Hepatocellular Carcinoma Assessment Randomized Protocol (SHARP) trial (6). Sorafenib has demonstrated a good safety profile in multiple clinical trials. However, adverse drug-associated events are common, sometimes severe, and particular attention should be paid to cardiovascular adverse events, particularly in patients with risk factors or known heart disease (6-8).

Provided with this evidence, our present study reports the case of a patient affected by highly enhancing advanced HCC in cirrhotic liver, who died during successful sorafenib monotherapy.

\section{Case report}

In March 2014, a 51-year-old man presented to the emergency department (ED) with intense and persistent pain in the upper right abdomen. A former history of drug addiction, no relevant disease and no cardiovascular risk factors were referred. In the ED, a chest X-ray, electrocardiogram (ECG) and measurement of troponin I was-performed, all revealing no alterations. Abdominal ultrasound demonstrated a cirrhotic pattern of the right hepatic lobe, with multiple and variously sized confluent nodules; portal vein thrombosis was also present, and HCC in cirrhotic liver was suspected. Blood tests revealed signs of liver failure [international normalized ratio (INR) 1.7, albumin, $2.7 \mathrm{~g} / \mathrm{dl}$, total bilirubin, $3.1 \mathrm{mg} / \mathrm{dl}$ ] with a Child-Pugh score of B8 and a Model for End stage Liver Disease (MELD) score of 17, hyper-transaminasemia (glutamic oxaloacetic transaminase, $94 \mathrm{U} / 1$, glutamic pyruvic transaminase 41/1), serological evidence of past hepatitis B virus infection, anti-hepatitis $\mathrm{C}$ virus positivity, and a marked increase in $\alpha$-fetoprotein 

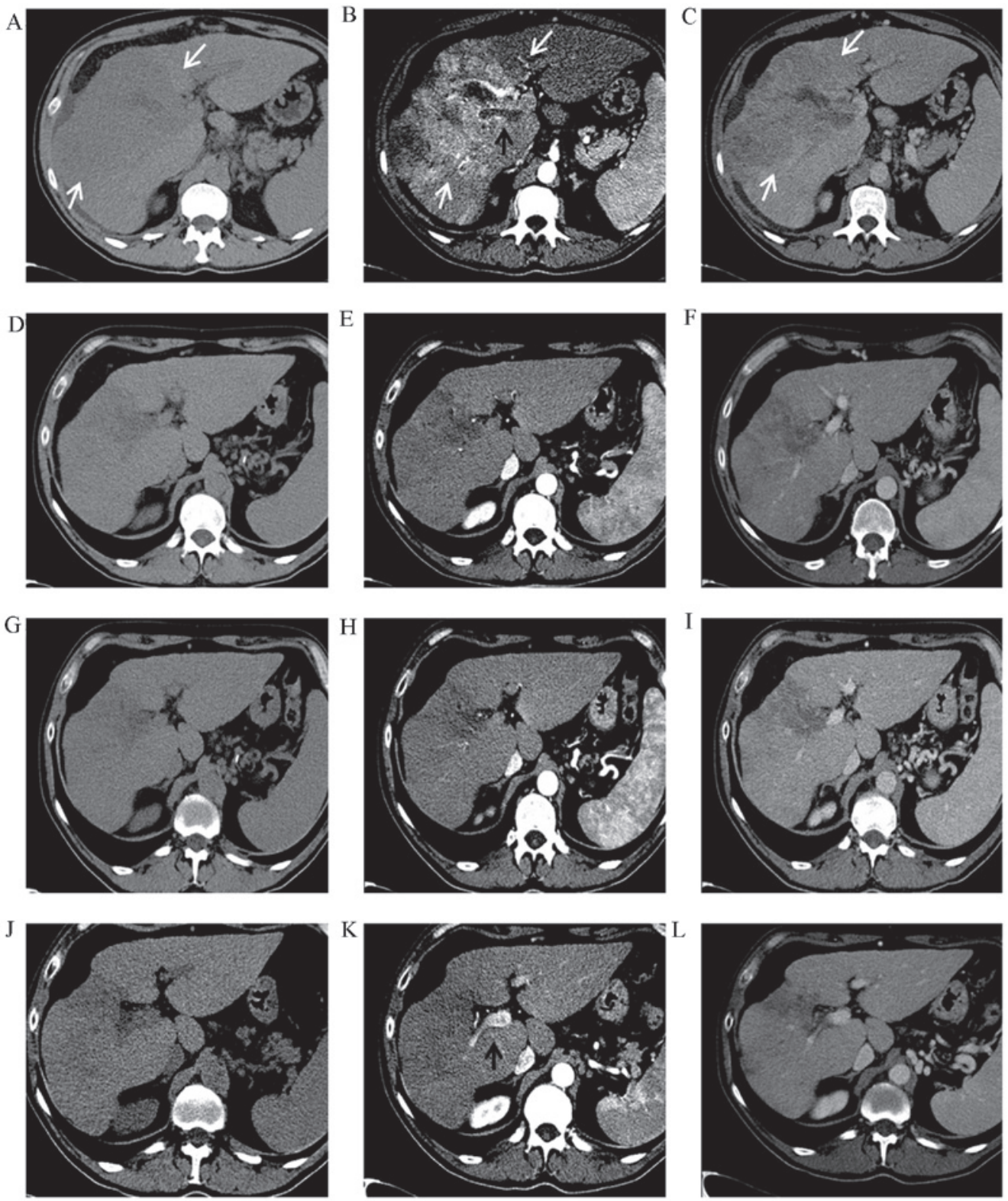

Figure 1. Abdominal enhanced CT scans at the baseline, determined after 3, 4 and 7 months. (A) Abdominal unenhanced and enhanced CT baseline (March 2014) during the (B) arterial and (C) portal phases revealed multiple merging nodular lesions in the right hepatic lobe (illustrated by the white arrows). (B) The liver nodules present a marked enhancement in the arterial phase. Malignant thrombosis of the portal vein's right branches is present (denoted by the black arrow). (D-L) Unenhanced (D, G and J) and enhanced (E, H and K) CT during arterial and portal (F, I and L) phases after 3 (June 2014), 4 (July 2014) and 7 months demonstrated a progressive reduction in the size of the right hepatic lobe lesions, with significant devascularization. (K) Portal vein recanalization was also observed (denoted by the black arrow). CT, computed tomography.

(695,000 ng/ml). Esophagogastroduodenoscopy revealed the presence of F2-grade esophageal varices, with no red marks and hypertensive gastropathy, whereby treatment with a non-cardio-selective $\beta$-blocker (propranolol, $60 \mathrm{mg}$ /day) was immediately started. An abdominal-enhanced Computed Tomography (CT) and a liver-specific gadolinium enhanced magnetic resonance imaging (MRI) examination confirmed the presence of multiple merging nodular lesions in the right hepatic lobe (12x8 cm overall diameter). The liver nodules also presented marked enhancement in the arterial phase (Fig. 1A-C; denoted by the white arrows). The CT enhancement rate $\left(\mathrm{D} \%_{\mathrm{arr}}\right)$ was calculated based on the mean density value from regions of interest (ROIs) drawn [expressed in Hounsfield Units (HU)] on an arterial phase (HU arterial) and on unen- hanced acquisition (HU unenhanced) using the following equation: $\mathrm{D} \%_{\text {art }}=$ (HU arterial-HU unenhanced $) / \mathrm{HU}$ unenhanced (9-12). It was estimated at $120 \%$.

The MRI examination revealed low proton diffusivity, as a sign of high cellular density and architectural disorder [apparent diffusion coefficient (ADC) lesion, $0.74 \times 10^{-3} \mathrm{~mm}^{2} / \mathrm{sec}$ vs. ADC parenchyma, $0.92 \times 10^{-3} \mathrm{~mm}^{2} / \mathrm{sec}$ (Fig. $2 \mathrm{~A}$ and B). Portal vein thrombosis (particularly in the right branches) (Fig. 1B, black arrow), signs of portal hypertension with splenomegaly $(14 \mathrm{~cm})$, collateral spleno-renal circulation, recanalization of the umbilical vein and ascites were also present. The patient was subsequently diagnosed with class $\mathrm{C} \mathrm{HCC}$ according to the BCLC classification system (2), and a full-dose oral sorafenib treatment $(800 \mathrm{mg} / \mathrm{day})$ was commenced in April 2014. The 

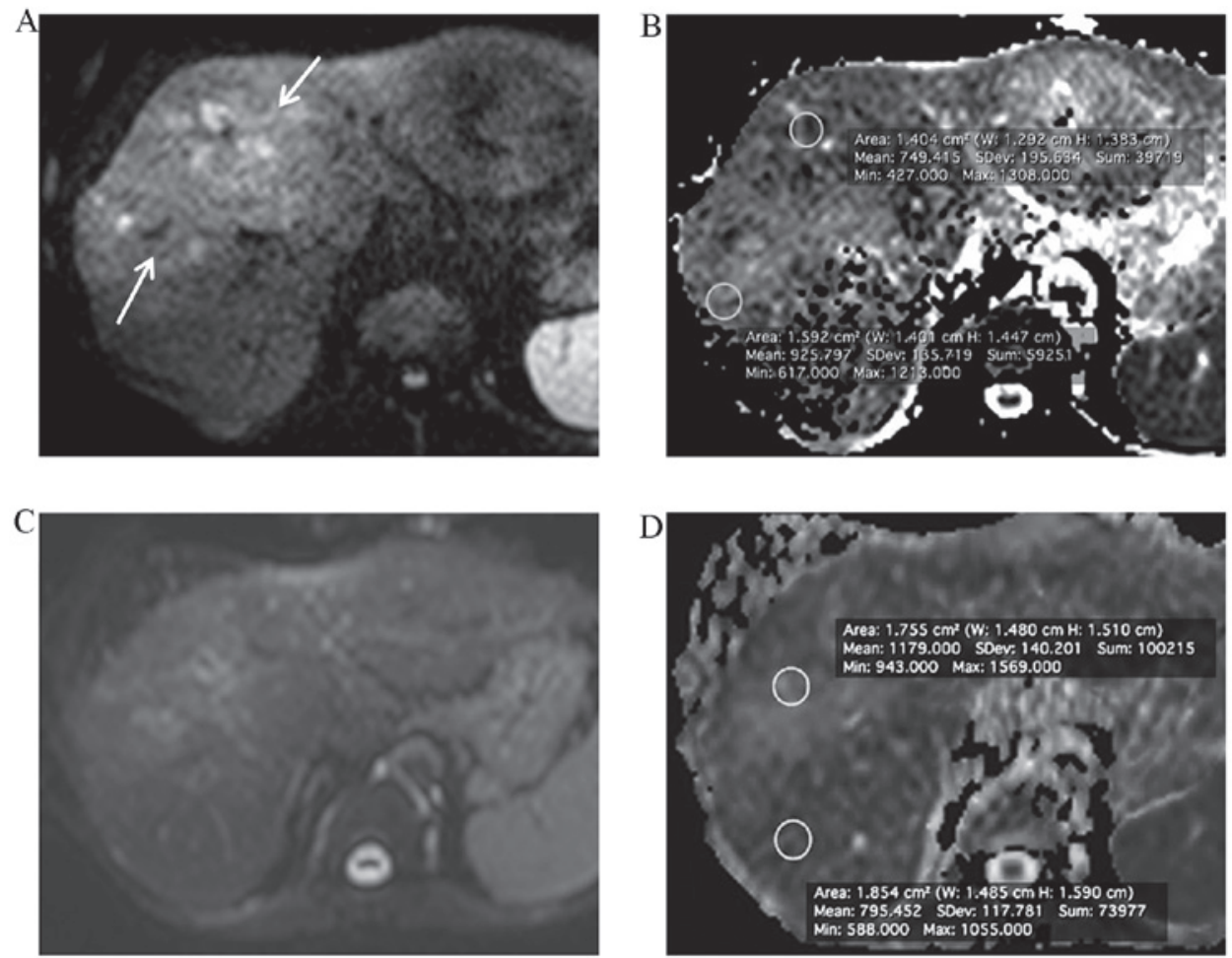

Figure 2. Abdominal enhanced MRI scans at the baseline and after 3 months. (A and B) MRI, heavily diffusion-weighted axial scan at the baseline (March 2014) revealed high signal intensity of the merging nodular lesions in the (A) right hepatic lobe illustrated by the white arrows. (B) The ADC map demonstrated a low ADC value of the lesion $\left(0.74 \times 10^{-3} \mathrm{~mm}^{2} / \mathrm{sec}\right.$; top circle) vs. ADC parenchyma $\left(0.92 \times 10^{-3} \mathrm{~mm}^{2} / \mathrm{sec}\right.$; bottom circle). (C and D) Following 3 months of therapy (June 2014), the MRI control revealed (C) no diffusion restriction with (D) ADC increase in the ADC map (ADC lesion, $1.17 \times 10^{-3} \mathrm{~mm}^{2} / \mathrm{sec}$; top circle, vs. ADC parenchyma, $0.79 \times 0^{-3} \mathrm{~mm}^{2} / \mathrm{sec}$, bottom circle).

administered dose was reduced to $400 \mathrm{mg} /$ day after 3 weeks, as diarrhea and hand-foot syndrome had occurred. In May 2014 , the patient was in a generally good medical condition.

The blood tests revealed an improvement of liver function (INR, 1.2, albumin, $3.2 \mathrm{~g} / \mathrm{dl}$, total bilirubin, $1.5 \mathrm{mg} / \mathrm{dl}$ ) with a Child-Pugh rating of A6 and MELD score of 10, and a marked reduction in the level of $\alpha$-fetoprotein $(3,647 \mathrm{ng} / \mathrm{ml})$. Enhanced CT imaging (Fig. 1D-F) demonstrated a reduction in size of the right hepatic lobe lesions (overall diameter, $10 \times 7 \mathrm{~cm}$ ) with signs of significant devascularization (D\% $\%_{\text {art }}$ of $40 \%$ ); portal vein thrombosis and ascites reduction were also observed. MRI diffusion-weighted acquisitions revealed an increase in the $\mathrm{ADC}$ lesion (ADC lesion, $1.17 \times 10^{-3} \mathrm{~mm}^{2} / \mathrm{sec}$ vs. ADC parenchyma, $0.79 \times 10^{-3} \mathrm{~mm}^{2} / \mathrm{sec}$ ) (Fig. $2 \mathrm{C}$ and D). According to the modified Response Evaluation Criteria in Solid Tumors (mRECIST) criteria (13), the patient was categorized as a partial responder, and treatment with sorafenib $(400 \mathrm{mg} / \mathrm{day})$ was therefore continued. After three (July 2014) and six (October 2014) months of therapy, enhanced CT revealed progressive reduction of both the liver lesion size (overall diameter, $8 \times 5.5$ and $7 \times 5 \mathrm{~cm}$, respectively) and contrast enhancement (30 and 25\% D\% art, respectively), internal necrotic component increment, portal vein thrombosis reduction, recanalization of the right portal branch for the VI-VII segments and no ascites (Fig. 1G-L). The patient continued to be in a good general condition with stable liver function and a further reduction in $\alpha$-fetoprotein levels $(150 \mathrm{ng} / \mathrm{ml})$, based on the blood tests.

In November 2014, while the possibility of radical surgical treatment was under evaluation, the patient's wife informed us that, after breakfast, the patient had complained of epigastric and retrosternal pain with general discomfort, and quickly succumbed to mortality within $10 \mathrm{~min}$. The patient's personal physician determined that he most likely succumbed to sudden cardiac death.

\section{Discussion}

In our opinion, there are three elements of interest about this case: i) The rapid response to sorafenib monotherapy; ii) the progressive decrease in the lesion's CT enhancement rate during sorafenib monotherapy; and iii) the possible correlation between sudden cardiac death and sorafenib therapy.

The SHARP (6) and Asia-Pacific (7) studies revealed that overall survival, the primary endpoint, was significantly longer in sorafenib-treated patients (10.7 vs. 7.9 months and 6.5 vs. 4.2 months, respectively) compared with the placebo group. However, the incidence of an objective response to sorafenib monotherapy was low. The partial response (PR) rate in the sorafenib group was 2.0 vs. $1.0 \%$ (SHARP) and 3.3 vs. $1.3 \%$ (Asia-Pacific) compared with the placebo group (6,7). Only ten case reports of advanced HCC revealing a complete response (CR)/PR to sorafenib monotherapy are present in the literature, published between 2008 and 2011 (Table I) (14-19). In a multicenter study published in 2014 by Shiba et al, only 18 of $3,047(0.6 \%)$ patients who were administered sorafenib monotherapy at institutions belonging to the Liver Cancer Study Group of Japan obtained a CR (20). The rapid response to therapy observed in the present study is unusual, and the reasons as to why this happens have yet to be fully elucidated. One possible explanation could be the oncogenic pathway 


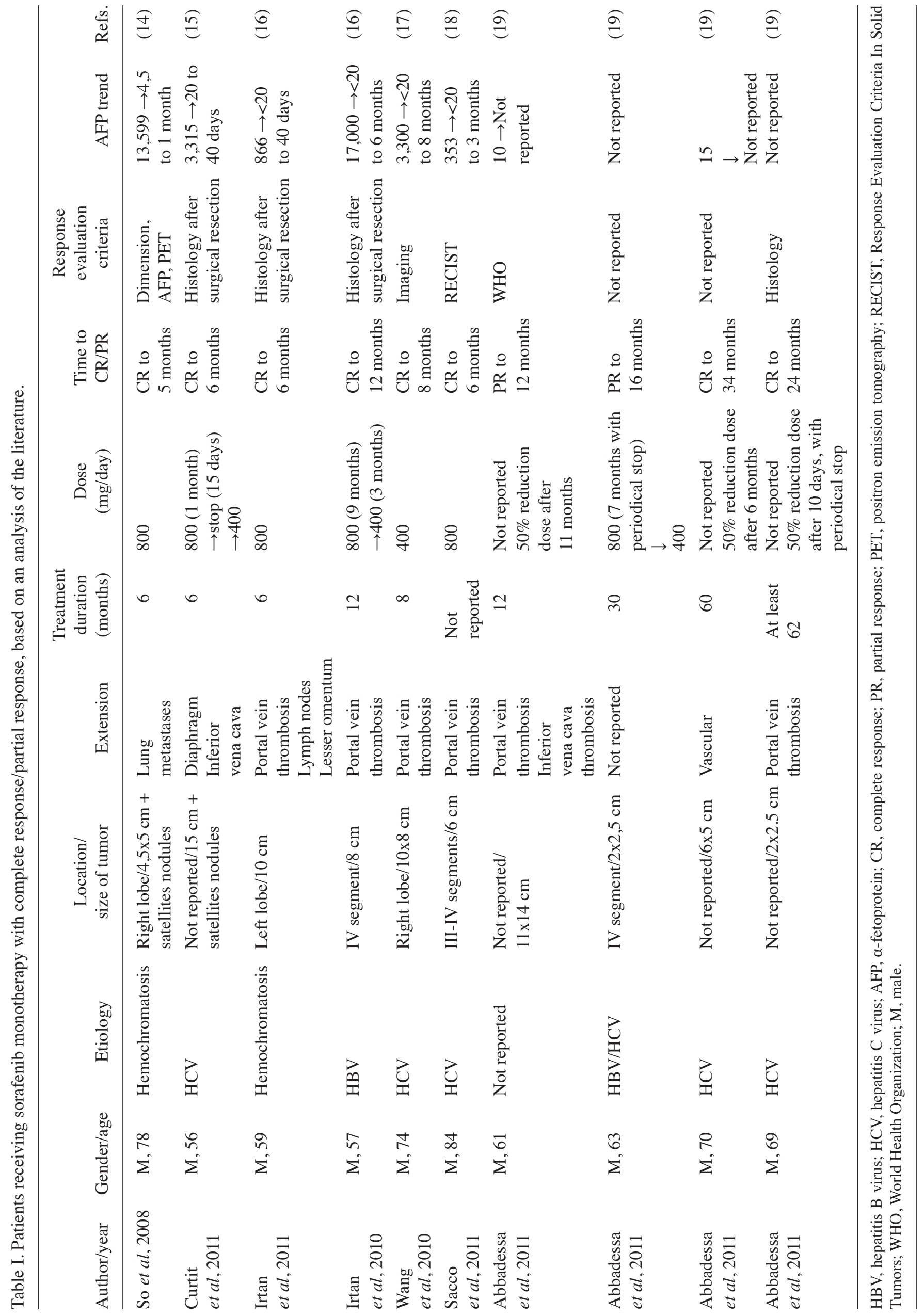




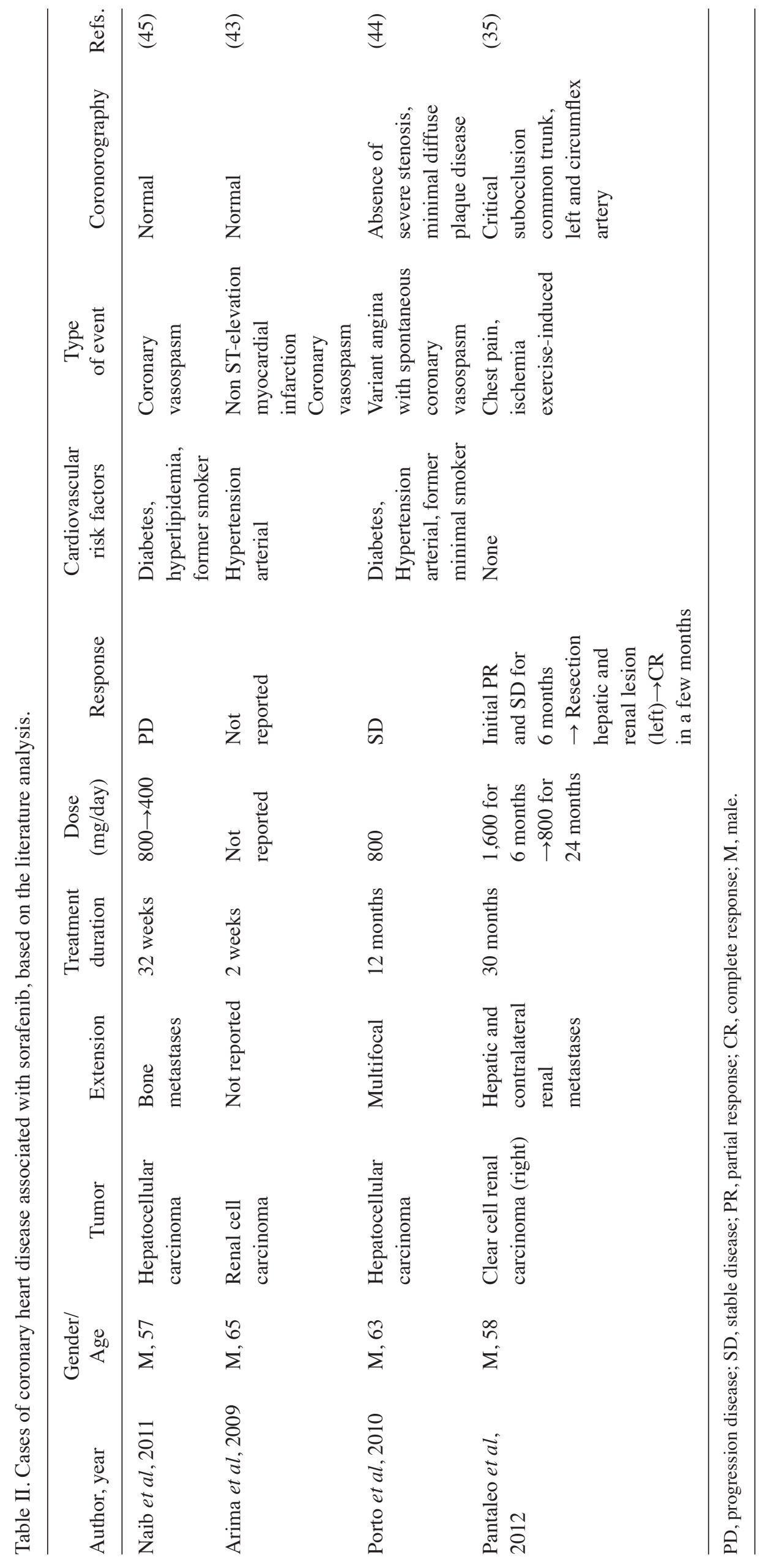


followed by HCC. According to certain authors $(17,21)$, there are two principal pathways for HCC oncogenesis, with a smaller number of $\mathrm{HCC}$ cases arising from the dysregulation of only a few intracellular molecular pathways, such as the RAF or vascular endothelial growth factor receptor (VEGFR)-mediated cascades targeted by sorafenib, and the vast majority of HCC cases instead being generated by several genetic or biomolecular alterations $(17,21)$. Since sorafenib specifically targets the RAF and VEGF pathways, multiple mutations could explain the resistance to molecular-targeted treatment in the majority of the patients. Despite previous attempts at doing so, it is not yet possible to identify reliable plasma, cancer and genetic biomarkers that enable the prediction of prognoses and the response to therapy with sorafenib in patients with advanced HCC (22-26). A previous study established that an early response of $\alpha$-fetoprotein (defined as a reduction $>20 \%$ from the baseline within the first 4 weeks of treatment) is an index of progression-free survival and overall survival in patients with HCC treated with anti-angiogenic drugs (27). Nevertheless, there are examples in the literature that highlight a delayed $\alpha$-fetoprotein response, followed by disease remission (28). Our patient also presented with malignant portal vein thrombosis (a common feature), as shown in Table I. Sorafenib proved to be effective against portal neoplastic thrombosis through the inhibition of the VEGF cascade (29). The partial recanalization of the portal venous system corroborates the hypothesis that sorafenib has a direct action on tumor cells invading the portal system and a modulation effect on the production of pro-thrombotic cytokines by the neoplastic cells $(18,30)$.

From the imaging point of view, as also described by other authors $(31,32)$, in the present study a marked response to treatment in a highly enhancing lesion was observed. Such a response can be defined in terms of nodule devascularization (D\% art reduction from 120 to $30 / 24 \%$ in our case), diameter stability, and, in a small number of cases, consistent volume decrease (maximum diameter reduction from 12 to $7 \mathrm{~cm}$ ). By contrast, minor, or no, significant responses in low-enhancing nodules were noted. An increase in the ADC value was also observed: This could be interpreted as a reduction in the cellularity and a higher diffusivity (33). Pretreatment stratification of patients based on the enhancement rate of the lesions may yield more interesting insights in terms of the response to therapy (32). In fact, sorafenib's predominant mechanism of action is the inhibition of angiogenesis via actions on the VEGF and platelet-derived growth factor systems (34). As demonstrated in other conditions of anticancer therapy, a higher expression of the target system (in this case, tumor vascularization) increases the effects of the targeted treatment.

In our case, the patient probably experienced sudden cardiac death. It may be hypothesized that the devascularization induced by sorafenib and its cardiovascular adverse effects are associated. In the literature, three cases of severe cardiovascular complications in patients with a sorafenib monotherapy CR have been reported. With the exception of a case of renal cell carcinoma reported by Pantaleo et al (35), shown in Table II, Hagihara et al (36) and Shiozawa et al (37) reported CR of HCC treated with sorafenib following the failure of pretreatments (surgery, trans-arterial chemioembolization and percutaneous ethanol injection) and complicated by acute myocardial and cerebellar infarction, respectively.

The problems associated with the side-effects of sorafenib are indeed relevant. Certain of the most common adverse events (fatigue, diarrhea, hand-foot syndrome, bleeding, arterial hypertension, elevation of aminotransferase and/or bilirubin) appear to be more frequent and more severe than has generally been reported in the registration trials (6). Furthermore, the majority of these adverse effects, particularly the cardiovascular effects (hypertension, bleeding complications, arterial thromboembolic events and cardiac events), can be serious and potentially fatal (38). Previous studies reported that cardiotoxicity is a rare adverse event of sorafenib (8). The SHARP study identified no statistically significant differences in terms of severe adverse events, including myocardial infarction or ischemia, between the sorafenib and the placebo groups (3 vs. 1\%) (6). Escudier et al (39) and Kane et al (40) reported an ischemia and/or myocardial infarction incidence in the sorafenib group of 4.9 and $2.7 \%$, respectively. In a Phase I study that included patients with different types of cancer treated with sorafenib, Tolcher et al (41) reported that the effects of the drug on certain cardiovascular parameters (QT interval, ECG, left ventricular ejection fraction, blood pressure and heart rate) were modest, and therefore of limited clinical relevance. On the other hand, Schimidinger et al (42) reported that $33.8 \%$ of the patients treated with a TKI (sunitinib or sorafenib) experienced a cardiac event (42). An analysis of the literature reveals four cases of coronary heart disease associated with sorafenib: Three cases (43-45) were associated with the presence of known cardiovascular risk factors and were due to arterial vasospasm; in one case, there was evidence of coronary artery stenosis (Table II) (35). There are elements in common between the oncogenic pathways and those that regulate cardiomyocyte hypertrophy and survival, which could account for sorafenib's cardiovascular toxicity (46). For Ederhy et al (47) and Force et al (48), heart damage occurs as the direct consequence of the inhibition of cardiomyocyte survival through the interruption of the extracellular-signal-regulated kinase (ERK) kinase cascade mediated by the blockade of RAF kinase- 1 and BRAF. However, studies on rat pups' myocytes have not supported this hypothesis (49).

The inhibition of RAF kinase and its downstream mediators, including mitogen-activated protein kinase kinase (MEK), may involve the stimulation of a small GTP-ase (RhoA) and its effector (Rho-associated protein kinase, or ROCK): This increases the $\mathrm{Ca}^{2+}$ sensitization of smooth muscle cells, leading to coronary hyper-contraction (43).

By inhibiting VEGF production, sorafenib also impairs nitric oxide (NO)- and prostacyclin (PG12)-mediated vasodilation, and, at the same time, promotes endothelin-1-induced vasoconstriction (50). Kawabata et al (51) have also observed that downregulation of stanniocalcin 1 (STC 1), a gene that serves a cardioprotective role, is responsible for the cardiotoxicity induced by sorafenib through the generation of reactive oxygen species.

In conclusion, sorafenib monotherapy is rarely able to induce a massive decrease in HCC nodule(s), and this appears to be even more likely as far as highly enhancing HCC nodules 
are concerned. Since it is possible that those who show a good response to sorafenib treatment also experience a higher incidence of adverse cardiovascular events, improved cardiological surveillance would be advisable in these patients, even in the absence of known cardiovascular risk factors.

\section{References}

1. Ferlay J, Soerjomataram I, Dikshit R, Eser S, Mathers C, Rebelo M, Parkin DM, Forman D and Bray F: Cancer incidence and mortality worldwide: Sources, methods and major patterns in GLOBOCAN 2012. Int J Cancer 136: E359-E386, 2015.

2. Forner A, Llovet JM and Bruix J: Hepatocellular carcinoma. Lancet 379: 1245-1255, 2012.

3. Oken MM, Creech RH, Tormey DC, Horton J, Davis TE, McFadden ET and Carbone PP: Toxicity and response criteria of the Eastern Cooperative Oncology Group. Am J Clin Oncol 5: 649-655, 1982.

4. Pugh RN, Murray-Lyon IM, Dawson JL, Pietroni MC and Williams R: Transection of the oesophagus for bleeding oesophageal varices. Br J Surg 60: 646-649, 1973

5. Liu L, Cao Y, Chen C, Zhang X, McNabola A, Wilkie D, Wilhelm S, Lynch $\mathrm{M}$ and Carter C: Sorafenib blocks the $\mathrm{RAF/MEK/ERK} \mathrm{pathway,} \mathrm{inhibits} \mathrm{tumor} \mathrm{angiogenesis,} \mathrm{and}$ induces tumor cell apoptosis in hepatocellular carcinoma mode PLC/PRF/5. Cancer Res 66: 11851-11858, 2006.

6. Llovet JM, Ricci S, Mazzaferro V, Hilgard P, Gane E, Blanc JF, de Oliveira AC, Santoro A, Raolul JL, Forner A, et al: Sorafenib in advanced hepatocellular carcinoma. N Engl J Med 359: 378-390, 2008

7. Cheng AL, Kang YK, Chen Z, Tsao CJ, Qin S, Kim JS, Luo R, Feng J, Ye S, Yang TS, et al: Efficacy and safety of sorafenib in patients in the Asia-Pacific region with advanced hepatocellular carcinoma: A phase III randomized, double-blind, placebo-controlled trial. Lancet Oncol 10: 25-34, 2009.

8. Escudier B, Eisen T, Stadler WM, Szczylik C, Oudard S, Siebels M, Negrier S, Chevreau C, Solska E, Desai AA, et al: Sorafenib in advanced clear-cell renal-cell carcinoma. N Engl J Med 356: 125-134, 2007.

9. Verstraete KL, Van der Woude HJ, Hogendoorn PC, De-Deene Y, Kunnen M and Bloem JL: Dynamic contrast-enhanced MR imaging of musculoskeletal tumors: Basic principles and clinical applications. J Magn Reson Imaging 6: 311-321, 1996.

10. Choi H, Charnsangavej $\mathrm{C}$, de Castro Faria S, Tamm EP, Benjamin RS, Johnosn MM, Macapiniac HA and Podoloff DA CT evaluation of the response of gastrointestinal stromal tumors after imatinibmesylate treatment: A quantitative analysis correlated with FDG PET findings. AJR Am J Roentgenol 183: $1619-1628,2004$.

11. Namkung S, Zech CJ, Helmberger T, Reiser MF and Schoenberg SO: Superparamagnetic iron oxide (SPIO)-enhanced liver MRI with ferucarbotran: Efficacy for characterization of focal liver lesions. J Magn Reson Imaging 25: 755-765, 2007.

12. Santoro L, Grazioli L, Filippone A, Grassedonio E, Belli G and Colagrande S: Resovist enhanced MR imaging of the liver: Does quantitative assessment help in focal lesion classification and characterization? J Magn Reson Imaging 30: 1012-1020, 2009.

13. Lencioni R and Llovet JM: Modified RECIST (mRECIST) assessment for hepatocellular carcinoma. Semin Liver Dis 30: $52-60,2010$.

14. So BJ, Bekaii-Saab T, Bloomston MA and Patel T: Complete clinical response of metastatic hepatocellular carcinoma to sorafenib in a patient with hemochromatosis: A case report. J Hematol Oncol 1: 18, 2008 .

15. Curtit E, Thiery-Vuillemin A, Nguyen T, Heyd B, Pivot X, Di Martino V and Borg C: Complete histologic response induced by sorafenib in advanced hepatocellular carcinoma: A case report. J Clin Oncol 29: e330-e332, 2011.

16. Irtan S, Chopin-Laly X, Ronot M, Faivre S, Paradis V and Belghiti J: Complete regression of locally advanced hepatocellular carcinoma induced by sorafenib allowing curative resection. Liver int 31: 740-743, 2011

17. Wang SX, Byrnes A, Verma S, Pancoast JR and Rixe O: Complete remission of unresectable hepatocellular carcinoma treated with reduced dose of sorafenib: A case report. Target Oncol 5: 59-63, 2010.
18. Sacco R, Bargellini I, Gianluigi G, Bertini M, Bozzi E, Altomare E, Battaglia V, Romano A, Bertoni M, Capria A, et al: Complete response for advanced liver cancer during sorafenib therapy: Case report. BMC Gastroenterol 11: 4, 2011.

19. Abbadessa G, Rimassa L, Pressiani T, Carrillo-Infante C, Cucchi E and Santoro A: Optimized management of advanced hepatocellular carcinoma: Four long-lasting responses to sorafenib. World J Gastroenterol 17: 2450-2453, 2011.

20. Shiba S, Okusaka T, Ikeda M, Saito H and Ichida T: Characteristics of 18 patients with hepatocellular carcinoma who obtained a complete response after treatment with sorafenib. Hepatol Res 44: 1268-1276, 2014.

21. DU J, Qian X and Liu B: Long-term progression-free survival in a case of hepatocellular carcinoma with vertebral metastasis treated with a reduced dose of sorafenib: Case report and review of the literature. Oncol Lett 5: 381-385, 2013.

22. Ozenne V, Paradis V, Pernot S, Casteinau C, Vullierme MP, Bouattour M, Valla D, Farges O and Degos F: Tolerance and outcome of patients with unresectable hepatocellular carcinoma treated with sorafenib. Eur J Gastroenterol Hepatol 22: 1106-1110, 2010.

23. Llovet JM, Peña CE, Lathia CD, Shan M, Meinhardt G and Bruix J; SHARP Investigators Study Group: Plasma biomarkers as predictors of outcome in patients with advanced hepatocellular carcinoma. Clin Cancer Res 18: 2290-2300, 2012.

24. Villanueva A and Llovet JM: Targeted therapies for hepatocellular carcinoma. Gastroenterology 140: 1410-1426, 2011

25. Villanueva A and Llovet JM: Impact of intra-individual molecular heterogeneity in personalized treatment of hepatocellular carcinoma. Hepatology 56: 2416-2419, 2012.

26. Lee YS, Kim BH, Kim BC, Shin A, Kim JS, Hong SH, Hwang JA, Lee JA, Nam S, Lee SH, et al: SLC15A2 genomic variation is associated with the extraordinary response of sorafenib treatment: Whole-genome analysis in patients with hepatocellular carcinoma. Oncotarget 6: 16449-16460, 2015.

27. Shao YY, Lin ZZ, Hsu C, Shen YC, Hsu CH and Cheng AL: Early alpha-fetoprotein response predicts treatment efficacy of antiangiogenic systemic therapy in patients with advanced hepatocellular carcinoma. Cancer 116: 4590-4596, 2010.

28. Huan HB, Lau WY, Xia F, Ma KS and Bie P: Complete response to sorafenib in a patient with recurrent hepatocellular carcinoma. World J Gastroenterol 20: 14505-14509, 2014

29. Li Q, Xu B, Fu L and Hao XS: Correlation of four vascular specific growth factors with carcinogenesis and portal vein tumor thrombus formation in human hepatocellular carcinoma. J Exp Clin Cancer Res 25: 403-409, 2006.

30. Novi M, Lauritano EC, Piscaglia AC, Barbaro B, Zocco MA, Pompili $\mathrm{M}$ and Gasbarrini A: Portal vein tumor thrombosis revascularization during sorafenib treatment for hepatocellular carcinoma. Am J Gastroenterol 104: 1852-1854, 2009.

31. Zhu AX, Holalkere NS, Muzikansky A, Horgan K and Sahani DV: Early antiangiogenic activity of bevacizumab evaluated by computed tomography perfusion scan in patients with advanced hepatocellular carcinoma. Oncologist 13: 120-125, 2008.

32. Jiang T, Zhu AX and Sahani DV: Established and novel imaging biomarkers for assessing response to therapy in hepatocellular carcinoma. J Hepatol 58: 169-177, 2013.

33. Mungai F, Pasquinelli F, Mazzoni LN, Virgili G, Ragozzino A, Quaia E, Morana G, Giovagnoni A, Grazioli L and Colagrande S: Diffusion-weighted magnetic resonance imaging in prediction and assessment of chemotherapy outcome in liver metastases. Radiol Med 119: 625-633, 2014.

34. Wilhelm SM, Carter C, Tang L, Wilkie D, McNabola A, Rong H, Chen C, Zhang X, Vincent P, McHugh M, et al: BAY 43-9006 exhibits broad spectrum oral antitumor activity and targets the RAF/MEK/ERK pathway and receptor tyrosine kinases involved in tumor progression and angiogenesis. Cancer Res 64 : 7099-7109, 2004.

35. Pantaleo MA, Mandrioli A, Saponara M, Nannini M, Erente G, Lolli C and Biasco G: Development of coronary artery stenosis in a patient with metastatic renal cell carcinoma treated with sorafenib. BMC Cancer 12: 231, 2012.

36. Hagihara A, Teranishi Y, Kawamura E, Fujii H, Iwai S, Morikawa H, Enomoto M, Tamori A and Kawada N: A complete response induced by 21-day sorafenib therapy in a patient with advanced hepatocellular carcinoma. Intern Med 52: 1589-1592, 2013.

37. Shiozawa K, Watanabe M, Ikcara T, Matsukiyo Y, Kogame M, Kanayama M, Matsui T, Kikuchi Y, Ishii K, Igarashi Y and Sumino Y: Sustained complete response of hepatocellular carcinoma with portal vein tumor thrombus following discontinuation of sorafenib: A case report. Oncol Lett 7: 50-52, 2014. 
38. Sivendran S, Liu Z, Portas LJ Jr, Yu M, Hahn N, Sonpavde G, Oh WK and Galsky MD: Treatment-related mortality with vascular endothelial growth factor receptor tyrosine kinase inhibitor therapy in patients with advanced solid tumors: A meta-analysis. Cancer Treat Rev 38: 919-925, 2012.

39. Escudier B, Eisen T, Stadler WM, Szczylik C, Oudard S, Staehler M, Negrier S, Chevreau C, Desai AA, Rolland F, et al: Sorafenib for treatment of renal cell carcinoma: Final efficacy and safety results of the phase III treatment approaches in renal cancer global evaluation trial. J Clin Oncol 27: 3312-3318, 2009.

40. Kane RC, Farrell AT, Madabushi R, Booth B, Chattopadhyay S, Sridhara R, Justice R and Pazdur R: Sorafenib for the treatment of unresectable hepatocellular carcinoma. Oncologist 14: 95-100, 2009.

41. Tolcher AW, Appleman LJ, Shapiro GI, Mita AC, Cihon F, Mazzu A and Sundaresan PR: Aphase I open-label study evaluating the cardiovascular safety of sorafenib in patients with advanced cancer. Cancer Chemother Pharmacol 67: 751-764, 2011

42. Schmidinger M, Zielinski CC, Vogl UM, Bojic A, Bojic M, Schukro C, Ruhsam M, Hejna M and Schmidinger H: Cardiac toxicity of sunitinib and sorafenib in patients with metastatic renal cell carcinoma. J Clin Oncol 26: 5204-5212, 2008.

43. Arima Y, Oshima S, Noda K, Fukushima H, Taniguchi I, Nakamura S, Shono M and Ogawa H: Sorafenib-induced acute myocardial infarction due to coronary artery spasm. J Cardiol 54: $512-515,2009$.
44. Porto I, Leo A, Miele L, Pompili M, Landolfi R and Crea F: A case of variant angina in a patient under chronic treatment with sorafenib. Nat Rev Clin Oncol 7: 476-480, 2010.

45. Naib T, Steingart RM and Chen CL: Sorafenib-associated multivessel coronary artery vasospasm. Herz 36: 348-351, 2011.

46. Hoshijima M and Chien KR: Mixed signals in heart failure: Cancer rules. J Clin Invest 109: 849-855, 2002.

47. Ederhy S, Izzedine H, Massard C, Dufaitre G, Spanp JP Milano G, Meuleman C, Besse B, Boccara F, Kahyat D, et al: Cardiac side effects of molecular targeted therapies: Towards a better dialogue between oncologists and cardiologists. Crit Rev Oncol Hematol 80: 369-379, 2011.

48. Force T, Krause DS and Van Etten RA: Molecular mechanisms of cardiotoxicity of tyrosine kinase inhibition. Nat Rev Cancer 7: 332-344, 2007.

49. Hasinoff BB and Patel D: Mechanisms of myocyte cytotoxicity induced by the multikinase inhibitor sorafenib. Cardiovasc Toxicol 10: 1-8, 2010.

50. Kamba T and McDonald DM: Mechanisms of adverse effects of anti-VEGF therapy for cancer. Br J Cancer 96: 1788-1795, 2007.

51. Kawabata M, Umemoto N, Shimada Y, Nishimura Y, Zhang B, Kuroyanagi J, Miyabe M and Tanaka T: Downregulation of stanniocalcin 1 is responsible for sorafenib-induced cardiotoxicity. Toxicol Sci 143: 374-384, 2015 